\title{
Three Decades of Lowest-low Fertility in Spain, 1991 - 2018
}

\author{
Albert Esteve ${ }^{1}$, Mariona Lozano ${ }^{1}$, Diederik Boertien ${ }^{1}$, Ryohei Mogi ${ }^{1}$, Qi Cui ${ }^{1}$ \\ ${ }^{1}$ Centre d'Estudis Demogràfics / CERCA Programme, Universitat Autònoma de Barcelona \\ Universitat Autònoma de Barcelona \\ C/ ca n'Altayó, E2, 08193, Bellaterra, Spain
}

\begin{abstract}
There are plenty of theories on low fertility, but few studies have aimed to measure and quantify the relative importance of various obstacles to fertility for explaining differences between desired and actual fertility. We aim to fill this gap by using data from the 2018 Fertility Survey $(14,556$ women and 2.619 men) for Spain, a country with one of the lowest levels of fertility in the world. Data on ideal family size, intended fertility, and reported reasons for not yet having (more) children allow us to estimate the extent of unrealized fertility as well as the reported relative importance of economic, health, and partnership related reasons for unrealized fertility. Results confirm that observed fertility is clearly below desired fertility in Spain. Material reasons - associated with job insecurity, instability, economic resources - are the main reported reasons why women and men do not have the desired number of children. These reasons are followed by those related to partnership (not having a stable partner), and health (difficulties in conceiving). Estimates based on actual fertility, employment, and partnerships shows that having a stable partner between the ages of 25 and 35 is a proximate determinant of the transition to the first child.
\end{abstract}

Keywords: Low Fertility, Spain, Unrealized fertility, Obstacles. 
Esteve et al. Three Decades Lowest-low Fertility in Spain, 1991-2018

\section{Introduction}

Spain was in 1991, together with Italy, the first country in the world to register a total fertility rate below 1.3 children per woman (Kohler, et al., 2002). Three decades later, fertility is still below this threshold. According to estimates by the Spanish Statistical Office (INE), the fertility rate recorded in 2019 was 1.23 children for all women and 1.17 for those born in Spain. By birth cohort, none of the cohorts born in Spain since 1960 has reached 1.4 children per woman by the age of 40 . Despite these figures, which place Spain as one of countries with the highest percentage of older individuals in the world (United Nations, 2019), the causes of this low fertility have been little studied, mainly due to the lack of data. The release of fertility surveys has been sparse and irregular over time and Spain did not participate in the "Generations and Gender" program; which has allowed for numerous comparative studies in Europe (Kikat, et al., 2007; Mönkediek \& Bras, 2018). The release of the 2018 Fertility Survey (FS) ends two decades without a fertility survey conducted by the Spanish Statistical Office. Social researchers can now analyze the causes of low fertility in Spain based on a representative sample of 14,556 women and 2,619 men.

In this paper, we analyze the main results of this survey. Beyond the novelty of analyzing such recent data, the 2018 Fertility Survey has additional advantages that can help improve our understanding of low fertility beyond Spain's context. First, the survey combines two independent samples, one of women and the other of men, which makes it possible to compare results by sex. This has been unusual in past fertility studies, which were mainly focused on women's experiences. Second, and most notably, the survey asks directly about desired fertility and the reasons why women and men have not (yet) achieved their desired number of children. Using this information, we estimate the unrealized fertility, defined as the gap between observed fertility and desired fertility when the former is lower than the latter (Casterline \& Han, 2016). In addition, the 
information on reported reasons for not having (more) children allows us, to our knowledge for the first time, to quantify the relative importance of reported material, partner, and health-related reasons for not achieving desired fertility. Most research and theory on low fertility has focused on single determinants such as material conditions, employment or gender egalitarianism. However, the relative importance of different factors is not often quantified.

In short, we aim to (i) better understand the reproductive dynamics of one of the world's lowest fertility populations, (ii) discuss the fit of Spain in the main family theories, and (iii) provide new analytical tools for the study of low fertility by suggesting a new indicator based on unrealized fertility. We aim to achieve these goals empirically by examining the evolution of Spanish fertility for women and men born in Spain between 1962 and 1989. Subsequently, we investigate their fertility preferences in terms of ideal family size and the desire to have children in the next three years. We then analyze the reasons given by women and men for not having achieved the desired number of children and, next, we estimate this unrealized fertility according to the main reason that prevented it. Finally, we use retrospective questions asked in the survey to analyze the association between having a partner or stable employment and the transition to the first child.

\section{Theoretical Interpretations of Low Fertility and the Spanish Context}

When Spain crossed the threshold of 1.3 children per woman in 1991, low fertility in Europe was mainly explained by the theory of the second demographic transition (Van de Kaa, 1987; Lesthaeghe, 2010). Led by the Scandinavian countries, and within these by the more educated population, the fall in fertility rates below replacement level was accompanied by a delay in the age at marriage, increases in unmarried cohabitation, and a greater instability of unions. The second demographic transition emphasized ideational and cultural factors as the main agents of 
change based on the following reasoning: the processes of individualization, associated with increasing levels of well-being, would move the expectations and preferences of individuals away from the times and forms of the traditional family. This interpretation was supported by changes in values and the increasing tolerance towards non-traditional family forms that found in social surveys (Surkyn \& Lesthaeghe, 2004; Inglehart, 2008; Kuyper et al., 2013). Although the family changes expected by the second demographic transition have been generalized to most Western countries (Kiernan, 2001; Sobotka, 2004), and even extended to other regions of the world (Raymo, et al., 2009; Esteve, et al., 2012; Yu \& Xie, 2015), the interpretation of their causes has been questioned from two broad perspectives.

The first critique of second demographic transition theory argues that material causes prevail over ideational ones (Mills, et al. 2011; Kreyenfeld, 2010; Ruggles, 2015). People want but cannot have children. Precariousness and economic uncertainty would be the main obstacles to entering into a stable union and having children. In favor of this interpretation there are two main pieces of evidence. First, the ideal family size in low-fertility countries has remained at around two children over time (Sobotka, 2014; Hartnett, 2020). Second, people with higher education levels and, usually, greater purchasing power are those who, in several societies, have more stable couple relationships and end up having more children than people with lower levels of education (Jalovaara, et al., 2018). This dynamic would reinforce social disadvantages and inequalities (Perelli-Harris, et al., 2010).

The second critical perspective emphasizes the relationship between family dynamics and the evolution of gender roles in Western societies (McDonald, 2000). The entry of women into the labor market has put into question the traditional male breadwinner model based on the specialization of roles between spouses inside and outside the home (Becker, 1973; Oppenheimer, 
Esteve et al. Three Decades Lowest-low Fertility in Spain, 1991-2018

1988). Several authors have argued that the failure to consolidate a new alternative model has led to a period of instability that is unfavorable to partnership formation and childbearing. However, as gender equality advances and, more specifically, as men assume their share of responsibility over domestic tasks, a new gender balance and family model more favorable to couple formation and fertility could be consolidated (Esping-Andersen \& Billari, 2015). This interpretation was validated, and partly inspired, by the evolution of fertility rates in Scandinavian countries during the last two decades. After ten years of continued fertility declines, countries such as Sweden, Finland and Norway experienced a fertility rebound that fueled, among others, the gender revolution theory (Goldscheider, et al., 2015). However, recent studies show that fertility has fallen again in these countries (Jalovaara, et al., 2019; Comolli, et al. 2020). Due to poor evidence of an eventual fertility recovery, and the impact of the great economic recession of 2008, now aggravated by the Covid-19 crisis, material explanations have again gained strength (Seltzer, 2019; Matysiak, et al., 2020). Young people are facing difficulties to live independently from their parents, access housing and find stable jobs. Economic uncertainty shakes their lives and compromises their fertility plans (Vignoli et al., 2020).

Like other Southern European countries, Spain's position in these debates has fluctuated as its fertility and family indicators have changed. In the early 1980 s, when the postulates of the second demographic transition were formulated, Spain perfectly fulfilled the role of a traditional country. Its fertility was higher and earlier than that of countries like Sweden, marriage was the hegemonic route to stable partnership, and the divorce rates were low (Alberdi, 1999). Spain was a typical example of a conservative country, with Catholic values and a strong attachment to the family (Reher, 1998; Requena, 2005). From the 1990s onwards important changes have materialized in the family sphere. The average age at first union increased and the arrival of the 
first child was delayed (Castro-Martín, 1992; Castro-Martín, 1993; Miret-Gamundi, 1997). Fertility rates fell sharply (Castro-Martín \& Martín-García, 2013). Cohabiting couples, separations and divorces grew significantly (Solsona \& Simó-Noguera, 2007; Domínguez-Folgueras \& Castro Martín, 2013; Bernardi \& Martínez-Pastor, 2011). By educational level, the most educated population led these transitions. Some considered that Spain was fully entering the second demographic transition (Sobotka, 2008) and value surveys reflected this (Liebfroer \& Fokkema, 2008). For example, the degree of tolerance towards non-traditional family forms, and the degree of acceptance of homosexuality or euthanasia were comparable to that of other Western countries, including the Nordic countries (Abou-Chadi \& Finnigan, 2019; Serrano \& Heredia, 2018).

But Spanish fertility decline and its later stagnation at around 1.3 children per woman also fit with the postulates of the gender revolution (Goldscheider, et al., 2015). On the one hand, women's advances in education and labor market are unquestionable. The proportion of young women with college degrees exceed that of men in the same age bracket (Ortiz, Rodríguez-Menés, 2015; Esteve, et al., 2016), and women's participation in the labor market has grown considerably since 1985 (Guinea-Martín et al., 2018; Miret, 2018). However, unbalanced gender division of domestic work is greater in Spain than in other Western European countries, especially when compared to Scandinavian countries (Voicu, et al., 2009; Fahlén, 2016; Borràs et al., 2018). Spanish men devote two hours less to housework than women. This difference increases to three hours among couples with children (Moreno-Colom, 2017; Ajenjo \& García-Román, 2019). In countries such as Sweden or Norway, the difference is one hour (Moreno-Colom, 2017). Low fertility in Spain is, therefore, consistent with women's higher participation in the labor market and men's lower participation in domestic tasks. 
However, among scholars and national experts, material reasons to explain low fertility (e.g. unemployment, access to housing, precariousness) predominate over all others causes (Bernardi, et al., 2003; Castro-Martín \& Martín-García, 2016). Due to the scarcity of data, it is difficult to objectively establish the underlying causes of low fertility in Spain. The good quality of registry data used to measure fertility and the evolution of births contrasts with the scarcity of retrospective and/or longitudinal surveys and data. Spain has not participated in the Generations and Gender program and has not conducted regular fertility surveys over time. In the last three decades, three surveys have been conducted, but only two of them by the Spanish Statistical Office (INE), in 1999 and in 2018. In 2006, the Centro de Investigaciones Sociológicas conducted a smaller survey that had some technical problems with population weights.

The scarcity of data contrasts with the high interest that, demographically speaking, Spain has as a case-study. Spain is, together with Italy, the country with the longest lasting low fertility in the world. It also has the highest average age at first child in Europe and one of the highest levels of childless women in the world (Sobotka, 2017). Among women born in the mid-70s, one out of four will not become a mother (Esteve, et al., 2016). Along with low fertility, the decline of the population at childbearing ages is leading to a fall in the number of births since 2008 . The COVID-19 crisis will aggravate this situation. INE's first estimates point to a 20 percent drop in births in the months of December 2020 and January and February 2021 compared to the same months a year earlier. The fall in births and low fertility have a direct impact on the level of aging of the Spanish population. The United Nations estimates that $36.8 \%$ of the population will be over 65 years of age in 2050. This figure is only surpassed by South Korea (38.1\%) and Japan (37.7\%).

The analytical strategy and results we present below may be useful for countries that are in a similar situation (e.g. Italy, Japan, South Korea) and understanding differences between actual 
and desired fertility in low-fertility countries more generally. Starting from the concept of unrealized fertility, we propose a strategy to measure the influence of the different reported reasons why women and men have not had the children they wanted, and the weight of each reason according to age. In doing so, we want to show the diversity of factors that condition low fertility, identify them and measure their influence and, ultimately, guide the development of the theory.

\section{The 2018 Fertility Survey: Data Processing and Analysis.}

In 2016, the Spanish Statistical Office (INE) decided to conduct a new fertility survey. Interviews were conducted between January and March 2018 and the microdata were released in April 2019. The result was a survey with more than 180 questions distributed in ten thematic blocks ${ }^{1}$ and distributed among 14,556 women and 2,619 men from two independent samples. The survey is cross-sectional but includes retrospective questions on partnership, fertility, housing and employment trajectories of the interviewees ${ }^{2}$. Our study focuses on women and men born and living in Spain at the time of the survey. Foreign-born individuals were excluded from the analysis for two reasons. First, because not all of their fertility took place in Spain. Second, because the weight of foreign-born women's fertility on total fertility varies according to birth cohorts and this makes comparisons across cohorts difficult. After excluding women and men born abroad, our subsample included information on 13,128 women and 2,386 men. The results are weighted using survey weights.

Three variables are central to our analysis: observed fertility, desired fertility and reasons given for not having (more) children at the time of the survey. Observed fertility is measured by

\footnotetext{
1 1) Identification of the person and biographical data, 2) Household, 3) Housing, 4) Family of Origin, 5) Relationships, 6) Children, 7) Fertility, 8) Studies, 9) Occupation and Income, 19) Values and attitudes.

${ }^{2}$ A sample of life histories based on retrospective information from the 2018 Fertility Survey and harmonized according to Generations and Gender Programe criteria is available at [https://www.ggp-i.org/data/harmonized-histories/].
} 
the total number of biological and adopted children at the time of the survey and retrospective information on their birthdates is used to document how fertility develops with age. Desired fertility is measured by the intention to have one (more) child in the next three years ${ }^{3}$. We use this information to capture the desire to have children in 2018. Results are disaggregated by parity $(0$, 1, 2, or 3 and more children) and by age (18 to 49). Since fertility experience of these cohorts were very homogeneous (see Figure 1), we consider, although with caution, that the desires expressed in 2018 may be representative of a broader period and of the set of cohorts analyzed in this paper. This is reinforced by the evidence that the ideal number of two children per woman has not changed over the last three decades (Sobotka and Beaujouan, 2014).

Reasons why women and men have not achieved their desired number of children were collected from respondents by asking them to select a maximum of three options among 20 predetermined reasons, with the possibility of adding other reasons or obstacles. In total, this resulted in 35 reasons in the microdata released by the INE. 54.3 percent of women and men indicated only one reason, 27.4 percent marked two reasons and 18.2 percent three reasons. We have grouped these reasons into six categories (see Appendix 1) according to whether they reflect: (1) the desire not to have (more) children; (2) the desire to have them later; (3) not having the right partner; (4) not meeting the material, economic, and work-life balance conditions to have children; (5) health problems to get pregnant (6) and others.

Socioeconomic variables used in the analysis include Education measured in three levels low (no schooling or primary education; $38 \%$ of our sample), medium (compulsory secondary and post-compulsory secondary education; 6.3\%) and high (post-secondary vocational training and university studies, 35.7\%). Retrospective information from the survey is used to study the

\footnotetext{
${ }^{3}$ The original question is: "Do you intend to have one or more children in the next 3 years? And for pregnant respondents: "In addition to the child you are expecting, do you intend to have one or more children in the next 3 years?
} 
impact of partnership status (living together as a cohabiting or married couple or not) and employment status (having a permanent job, a temporary job or no job). Retrospective information was available for 10,917 women and 2,045 $\mathrm{men}^{4}$.

The analysis is structured as follows. First, we document trends in the total number of children and fertility rates for the cohorts of the sample studied. We have grouped the cohorts into groups of five generations starting with those born between 1965 and 1969 and ending at those born between 1985 and $1989^{5}$. Results are presented separately for men and women as well as by education. Second, we aim to give insight into fertility desires by presenting differences in the plans to have children within the next three years of the survey by age, parity and sex. To ease the interpretation of the figures, frequencies have been smoothed using a spline function ${ }^{6}$ (Camarda, 2012).

Third, we aim to quantify the gap between currently desired and observed fertility which we label 'unrealized fertility'. To this end we use information respondents provided about the reasons why they did not yet have children or why they did not yet have another child. We assume no gap in currently desired and observed fertility if individuals indicated that they did not have (more) children because they were too young or because they did not want (more) children. Subsequently, we calculated how high fertility were to be if individuals who reported material, partner-related, health or other obstacles would have a child. This procedure is described in detail

\footnotetext{
4 The data have been treated in two different ways. The first is cross-sectional, where we include information on all women and men responding to the survey, excluding those born abroad (13,128 women and 2,386 men). The second reconstructs the couple, fertility and labor market histories through the retrospective questions of the same survey. As a result, we lose $16.8 \%$ of cases for women and $14.3 \%$ for men. This loss of cases is due to two main reasons. First, we have limited the sample to persons born between 1965 and 1989 . The number of cases among the pre1965 generations was too few; those born after 1989 are too young to be considered. Secondly, the loss of cases is due to the lack of information on dates when the different events occurred, thus not being able to reconstruct the trajectory. We have performed sensitivity tests to check that the loss of cases does not alter either the magnitude or the meaning of the results.

${ }^{5}$ Cohorts between 1962 and 1964 were excluded from the sample due to small sample sizes. Women born between 1965 and 1989 account for $62.5 \%$ of the sample.

${ }^{6}$ Two smoothing techniques have been employed to generate Figures 3 and 4, namely the simple moving average and the P-spline model. First, we used the weighted average (the unweighted average of 9 data points) to highlight the overall trend of each category (e.g., Parity 0 , couple ratios). Second, we used a P-spline model to smooth each category.
} 
in Appendix 2 but relies on treating the respondents of the survey as a synthetic cohort based on their age at the time of the survey. Building on this assumption, we can calculate, for each age, the share of individuals that encounters a certain obstacle to fertility for the first time and wants to have (more) children. We subsequently simulate that these individuals give birth at that age instead of encountering the obstacle to fertility. We assume that reported main reasons are not replaced by other reasons, which is an unrealistic scenario but does allow us to quantify the relative importance of different types of reasons given. In a second step we also quantify the effect that these simulated births would have on higher parities. For the group of individuals that are simulated to give birth at each age we estimate the share that also gives a second and third birth based on the share of individuals who reach these parities before age 48 (among those that are observed to have given birth at that age). Results are presented disaggregated by sex and educational level.

Finally, we compare the extent to which reported reasons fit observed associations between employment, partnerships and fertility using retrospective histories. We constructed a person-year file where for each year we identified whether the person lived with a partner, had a permanent employment contract, and had a child. Subsequently, at each age, we calculate the probability of giving birth within the next three years among childless individuals depending on employment and partnership status.

\section{Results}

\section{Cohort Fertility}

The four panels in Figure 1 show the percentage of men and women that had at least one child and the cumulative fertility by age and birth cohort in Spain between 1965 and 1989. There are three main results that we aim to highlight. First, the proportion of people who have had at least one 
child among the cohorts analyzed does not exceed 75 percent of the total for both women and men. In addition, the total cumulative fertility among these same cohorts does not exceed 1.4 children per woman/man. Second, fertility behavior is very stable over time and across birth cohorts, except for females born between 1965-69, who had their first child slightly earlier than the rest. The cohorts are, therefore, very homogeneous in terms of their fertility behavior. Third, males' fertility is lower than females at all ages and in all cohorts. Men born between 1965 and 1969 record a fertility rate of 1.25 children for men, and this is 1.40 for women.

\section{[Insert Figure 1]}

Figure 2 shows the cumulative percentage of women and men who have been mothers and fathers by educational level. Highly educated women have children later than women with medium

or low levels of education. The proportion of mothers among women with higher levels of education is lower than for other women. This educational gradient is visible for all cohorts, although the gap narrows in some. For the 1975-79 cohort, the proportion of highly educated women who are mothers at age 35 has reached the level of women with medium education at the same age. Among men, differences by education are smaller than among women. Highly educated men have their first child slightly later than the other educational groups, but percentages tend to convergence after the age of 40 .

\section{[Insert Figure 2]}

\section{Intentions to Have Children within the Next Three Years}

Observed fertility in Spain is clearly below desired fertility. Figure 3 shows the percentage of women (left panel) and men (right panel) who reported at the time of the survey the desire to have 
a child in the next three years by age and parity (P1, P2 and P3 indicate parities at the time of the survey ). Dark colors indicate the intention to have a child in the next three years, and light colors the opposite. Due to the cross-sectional nature of the survey questionnaire, it is not possible to use retrospective information to longitudinally reconstruct preferences for having children. 18.5 percent of women and 20.7 percent of men indicated they intend to have a child in the next three years. Had these intentions materialized in the three years following the survey, and assuming an equal distribution of births over the three years, the total fertility rate of women born in Spain could have reached 2.3 in 2019 , which is almost double the observed fertility for the same year among Spanish-born women (1.17).

The intention to have children varies according to sex, age and the number of children that people already have. Men and women show similar patterns by age and parity, although the levels are slightly different. Before the age of 32 , the proportion of women who intend to have children is higher than that of men. After this age, intentions are higher among men. At 20 years old, less than 2 percent of women and men intend to have children in the next three years. The percentage increases rapidly with age until the age of 40. Most people who want to have children are childless or have, at most, one child, and are between 28 and 40 years old.

[Insert Figure 3]

\section{Estimates of Unrealized Fertility and Its Reasons}

Figure 4 shows the distribution of the reasons why women (left panel) and men (right panel) do not (yet) have the desired number of children at the time of the survey by age and parity. The figure also includes people who do not want to have (more) children. The proportion of people who are childless and who do not want children is below $10 \%$ at all ages displayed here. Before the age of 
Esteve et al. Three Decades Lowest-low Fertility in Spain, 1991-2018

25 , the majority of childless people reported being too young to have children. After this age, other reasons emerge. Reasons related to the lack of a partner are particularly important among the childless, and more so among men than women. Material reasons related to the economy and workfamily conflict are even more important than those related to partnerships and. These reasons mainly affect people between 25 and 40 years old who are childless or only have one child. From age 40 onwards, health problems related to the difficulty of conceiving have a higher incidence.

$$
\text { [Insert Figure 4] }
$$

In Table 1 we quantify the relative weight of different types of reported reasons in overall unrealized fertility, and treat the respondents interviewed as a synthetic cohort based on the age at the time of the survey. Results are shown by sex, parity and educational level of the Spanish-born population aged 18-48 in 2018. We focus on partner, material and health obstacles. We do not quantify the effect of 'not wanting to have children' or 'being too young' as we consider that these reasons to reflect people's fertility preferences and not the difficulties in achieving these preferences.

In this synthetic cohort, women's fertility (1.39) is higher than men's (1.21). Pooling the three categories of reasons together, unrealized fertility is estimated to be 0.6 children for women and 0.96 children for men. If we add these figures to observed fertility, women born in Spain would have reached 2 children per woman (1.99) and men would have surpassed this threshold (2.17) if fertility desires would have been met. Material reasons are the most important. Unrealized fertility due to material reasons is estimated at 0.29 children per woman and 0.42 children per man. Among men, partner-related reasons $(0.41)$ are just as important as material ones. Health-related reasons have a similar impact on unrealized fertility among women and men, at around 0.12 children. 
Esteve et al. Three Decades Lowest-low Fertility in Spain, 1991-2018

By parity, unrealized fertility is higher in the transition to the second than the first child. For example, material reasons hardly prevent women and men from having a first child, but delay the birth of this first child and, in turn, it reduces the probability of having a second child. Grouping the three reasons (partner, material and health) together, women's unrealized fertility for the second child is almost twice as high (0.25) as for the first child (0.13).

Women's unrealized fertility increases with educational level due to the higher incidence of reported material and partner reasons among women with higher education. Unrealized fertility is 0.70 children per highly educated woman and 0.5 per lower educated woman. Men show a different pattern. Unrealized fertility is higher at the extremes of the educational hierarchy, but due to different reasons. Partner obstacles prevail over material ones among low-educated men and, conversely, material reasons prevail over partner ones among highly educated men.

[Insert Table 1]

\section{Proximate Determinants of the Transition to the First Child}

In the last part of our analysis, we check to what extent the reported reasons match with the actual correlates of becoming a parent. We use the retrospective survey information to analyze whether childless women's and men's partnership and employment status are related to the probability of having a child in the next three years (see Figure 5). To do so, we build on the cohort perspective and use the retrospective data available in the survey. Regarding partnership status, we distinguished between those who were living with a partner and those who were not. Regarding employment, we classified respondents according to whether they had a permanent employment contract, a temporary contract, or no job. 
The probability of having a first child varies with age. The risk is relatively low before the age of 20, it peaks between 30 and 35 years old, and it decreases rapidly thereafter. Having and living with a partner increases the probability of having a first child among women and men between 20 and 40 years old. Within this age range, the importance of living with a partner on the probability of having a first child peaks between 25 and 35 years of age. In contrast, women's employment contract do not seem to explain the transition to the first child, even when considering their partnership status (results not shown). In contrast, the probability of having a child in the next three years is higher among men who have a permanent contract than among those who do not have a job or have a temporary contract. However, for both men and women, employment stability influences the timing of couples (results not shown). Those with a permanent job enter into a union earlier than unemployed or temporary workers.

[Insert Figure 5]

\section{Summary and Final Discussion}

In 2021, Spain celebrated 30 years since, for the first time in its history, fertility rated fell below 1.3 children per woman. Since then, women's fertility has mostly remained below this threshold. As a result, Spain has today one of the oldest populations in the world. In this paper, we studied the first fertility survey conducted by the Spanish statistical office published in twenty years. This is the first study that estimates the main reasons behind low fertility rates in Spain, and calculated the unrealized fertility. We highlight four major findings.

First, we confirm the structural nature of low fertility in Spain. The birth cohorts analyzed are very homogeneous in terms of low fertility and there is no sign of recovery among the youngest cohorts. Men have lower fertility than women. Second, observed fertility is clearly below desired 
fertility. If one out of three women who in 2018 expressed the intention to have children in the next three years had actually had a child in 2019 , the fertility rate in Spain would have reached 2.3 children per woman, which is almost two times the observed fertility rate recorded by the statistical office that same year among Spanish-born women: 1.17 children per woman. Third, material reasons related to economic and work-family conflict are the main reported reasons why women and men do not reach the desired number of children, followed by partner-related and health reasons. The unrealized fertility due to all these reasons is 0.6 children per woman and 0.96 children per man. Most of the unrealized fertility is observed in the second child. Delays in the transition to the first birth have a major impact on fertility not so much through increasing the number of childless individuals, but rather by shortening the time available for transitions to higher order births. Fourth, the retrospective analysis shows the importance of cohabitation between the ages of 25 and 35 as a proximate determinant of fertility. Women's stable employment is not a proximate determinant of fertility, but additional analysis shows it is a proximate determinant of entering into a union. Similarly, for the case of Germany, Kreyenfeld (2010) also found little evidence that that uncertainties in female employment careers generally led to a postponement in parenthood.

From a methodological point of view, in this article we have suggested and implemented a new method to measure unrealized fertility by analyzing the reported reasons why women and men do not reach their desired number of children. However, it must be noted that the crosssectional nature of the data, and the difficulty of measuring the simultaneity and complementarity between reasons, condition the interpretation of the results. Nonetheless, our findings are useful to the extent that they give insights into the relative importance given to various reasons for unrealized fertility. Our analytical strategy builds on the framework of proximate determinants of 
fertility (Bongaarts, 1978). Rather than focusing on one determinant of fertility we have aimed to exploit the tools available to demographers to analyze why women and men report do not have children from a population perspective. The method we propose to reach such a holistic picture has the advantage of capturing how the influence of different obstacles to fertility varies with age. In line with theoretical perspectives that have emphasized economic disadvantage as a major obstacle to fertility (Mills, et al. 2011; Kreyenfeld, 2010; Ruggles, 2015), we found material reasons to be most commonly reported by respondents. However, we also found that partnerrelated and, to a lesser extent, health reasons form important obstacles to fertility in Spain. This illustrates that focusing on a single factor is insufficient to understand fertility differences between countries. In addition, the results show that the role of having a partner merits more attention in theories about low-fertility.

From a theoretical perspective, our results suggest that ideational factors, typically associated with the second demographic transition, would explain why people do not consider having children before the age of thirty. Policies are therefore likely to have little effect on the fertility behavior of individuals below age 30 . However, after this age material and partner-related factors play a determining role. As our results also show that these obstacles primarily have an effect on fertility by preventing higher order births, obstacles to fertility still present after age 30 can have major consequences for levels of fertility. The age at which individuals fulfil material, partner and health-related conditions might therefore be an important determinant of fertility within Spain, and possibly also to explain cross-national variation in fertility. In our analysis of observed fertility, we found weak associations between having a stable job and becoming a parent in the three subsequent years. However, material factors are probably having an important impact on union formation, especially among men and, among them, those with lower levels of education. 
The conclusions of this paper have relevant implications for policy. In terms of fertility preferences, Spain is no different from other European countries (Sobotka \& Beaujouan, 2014). However, Spanish society does not take advantage of its full reproductive potential. Young people have great difficulties in accessing housing which delays the mean age at which they leave the parental home. This, in turn, delays the average age at which young people enter into stable partnerships, and hence shortens the time period to achieve their reproductive desires. Job insecurity, unemployment and economic uncertainty further limit the ability of young individuals to live independently. In order to ensure that young people can have their desired number of children, we need public policies to improve access to housing and better employment conditions. In Spain, unemployment and low salaries are relevant features for young workers, and hence, a more dynamic labor market is also needed to raise fertility rates to the desired levels. Transitions into cohabitation and marriage are also affected by the precarious working conditions of young people. The COVID-19 crisis will only aggravate the scenario for younger cohorts in terms of their achieved fertility. The first available data from the Spanish Statistical Office show a drop in births of more than 20 percent compared to the previous year for the months of December 2020, and January and February 2021. And these are probably only the most immediate effects. Delaying fertility on an already late calendar will have irreversible consequences on the proportion of women and men who will not manage to have any children and will increase the gap between desired fertility and observed fertility. 
Esteve et al. Three Decades Lowest-low Fertility in Spain, 1991-2018

\section{References}

Abou-Chadi, T., Finnigan, R. (2019). Rights for same-sex couples and public attitudes toward gays and lesbians in Europe. Comparative Political Studies, 52(6), 868-895.

Ajenjo, M., García-Román, J. (2019). La persistente desigualdad de género en el uso del tiempo en España. Perspectives Demogràfiques, 014, 1-4.

Alberdi, I. (1999). La nueva familia española (Vol. 10). Madrid: Taurus.

Baizán, P., Aassve, A., \& Billari, F. C. (2003). Cohabitation, marriage, and first birth: The interrelationship of family formation events in Spain. European Journal of Population/Revue européenne de Démographie, 19(2), 147-169.

Becker, G. S. (1973). A theory of marriage: Part I. Journal of Political Economy, 81(4), 813-846.

Bernardi, F., \& Martínez-Pastor, J. I. (2011). Divorce risk factors and their variations over time in Spain. Demographic Research, 24, 771-800.

Bernardi, F., Requena, M., \& de Revenga, D. (2003). La caída de la fecundidad y el déficit de natalidad en España. RES. Revista Española de Sociología, 3, 29-49.

Bongaarts, J. (1978). A Framework for Analyzing the Proximate Determinants of Fertility. Population and Development Review, 4 (1), 105- 32.

Borràs, V., Ajenjo, M., \& Moreno-Colom, S. (2018). More time parenting in Spain: A possible change towards gender equality? Journal of Family Studies, https://doi.org/10.1080/13229400.2018.1440618

Camarda, C.G. (2012). Mortality Smooth: An R package for smoothing Poisson counts with PSpline. Journal of Statistical Software, 50(1), 1-24. 
Esteve et al. Three Decades Lowest-low Fertility in Spain, 1991-2018

Casterline, J. B., \& Han, S. (2017). Unrealized fertility: Fertility desires at the end of the reproductive career. Demographic research, 36, 427-454.

Castro-Martin, T. (1992). Delayed childbearing in contemporary Spain: trends and differentials. European Journal of Population/Revue Européenne de Démographie, 8(3), 217-246.

Castro-Martin, T. (1993). Changing nuptiality patterns in contemporary Spain. Genus, 49(1-2), 79-95.

Castro-Martín, T. y T. Martín-García (2013), Fecundidad bajo mínimos en España: pocos

hijos, a edades tardías y por debajo de las aspiraciones reproductivas, en G. Esping-Andersen

(Coord.), El déficit de la natalidad en Europa. La singularidad del caso español, Barcelona: Obra Social

La Caixa, 48-88.

Castro-Martín, T.; Martín-García, T. (2016). La fecundidad en España: entre las más bajas del mundo y sin muchas perspectivas de recuperación, Panorama social 23, 11-26.

Comolli, C.L., Neyer, G., Andersson, G. et al. (2020). Beyond the Economic Gaze: Childbearing During and After Recessions in the Nordic Countries. European Journal of Population, https://doi.org/10.1007/s10680-020-09570-0

Esping-Andersen, G., \& Billari, F. C. (2015). Re-theorizing family demographics. Population and Development Review, 41(1), 1-31.

Esteve, A., Schwartz, C. R., Van Bavel, J., Permanyer, I., Klesment, M., \& Garcia, J. (2016). The end of hypergamy: Global trends and implications. Population and Development Review, 42(4), 615. 
Esteve et al. Three Decades Lowest-low Fertility in Spain, 1991-2018

Esteve, A., Devolder, D., Domingo, A., (2016) Childlessness in Spain: Tick Tock, Tick Tock, Tick Tock!, Perspectives Demogràfiques, 1, 1-4.

Fahlém, S. (2016). Equality at home - A question of career? Housework, norms, and policies in a European comparative perspective. Demographic Research, 35(48), 1441-1440.

Goldscheider, F., Bernhardt, E., Lappegard, T. (2015). The gender revolution: A framework for understanding changing family and demographic behaviour. Population and Development Review, 41(2), 207-239.

Guinea-Martin, D., Mora, R., \& Ruiz-Castillo, J. (2018). The Evolution of Gender Segregation over the Life Course. American Sociological Review, 83(5), 983-1019.

Hartnett, C. S., \& Gemmill, A. (2020). Recent trends in US childbearing intentions. Demography, 57(6), 2035-2045.

Inglehart, R. (2008). Changing values among western publics from 1970 to 2006. West European Politics, 31(1-2), 130-146.

Jalovaara , M., Neyer, G., Andersson, G., Dahlberg, J., Dommermuth, L., Fallesen, P., Lappegard, T. (2019). Education, Gender, and Cohort Fertility in the Nordic Countries. European Journal of Population, 35, 563-586.

Kohler, H. P., Billari, F. C., \& Ortega, J. A. (2002). The emergence of lowest-low fertility in Europe during the 1990s. Population and Development Review, 28(4), 641-680.

Kiernan, K. (2001). The rise of cohabitation and childbearing outside marriage in Western Europe. International journal of law, policy and the family, 15(1), 1-21.

Kreyenfeld, M. (2010). Uncertainties in female employment careers and the postponement of parenthood in Germany. European sociological review, 26 (3), 351-366. 
Kuyper, L., Iedema, J., \& Keuzenkamp, S. (2013). Towards tolerance. Exploring changes and explaining differences in attitudes towards homosexuality in Europe. The Hague, the Netherlands: Netherlands Institute for Social Research (SCP).

Lesthaeghe, R. (2010). The unfolding story of the second demographic transition. Population and Development Review, 36(2), 211-251.

Liefbroer, A. C., \& Fokkema, T. (2008). Recent trends in demographic attitudes and behaviour: Is the Second Demographic Transition moving to Southern and Eastern Europe? In J. Surkyn, J. v. Bavel, \& P. Deboosere (Eds.), Demographic challenges for the 21st century. A state of art in demography (pp. 115-141). Brussels: Brussels University Press.

Macarrón, A. (2011). El suicidio demográfico de España. Madrid: Homo Legens, SL.

Matysiak, A., Sobotka, T., \& Vignoli, D. (2020). The Great Recession and fertility in Europe: A sub-national analysis. European Journal of Population, 1-36. https://doi.org/10.1007/s10680020-09556-y

McDonald, P. (2000). Gender equity in theories of fertility transition. Population and Development Review, 26 (3), 427-439.

Mills, M., Rindfuss, R. R., McDonald, P., \& Te Velde, E. (2011). Why do people postpone parenthood? Reasons and social policy incentives. Human reproduction update, 17 (6), 848860.

Miret-Gamundi, P. (1997). Nuptiality patterns in Spain in the eighties. Genus, 53 (3-4), 183-198.

Miret, P. (2018), Composición demográfica de la fuerza de trabajo y el empleo, Gaceta Sindical, Reflexión y debate (Distribución de la renta, desigualdades y brechas sociales), 31: 271-283. 
Esteve et al. Three Decades Lowest-low Fertility in Spain, 1991-2018

Mönkediek, B., \& Bras, H. (2018). Family systems and fertility intentions: Exploring the pathways of influence. European Journal of Population, 34 (1), 33-57.

Moreno-Colom, S. (2017). The gendered division of housework time: Analysis of time use by type and daily frequency of households tasks. Time and Society, 26 (1), 3-27.

Morgan, S. P., \& Rackin, H. (2010). The correspondence between fertility intentions and behavior in the United States. Population and Development Review, 36 (1), 91-118.

Oppenheimer, V. K. (1988). A theory of marriage timing. American Journal of Sociology, 94(3), 563-591.

Ortiz, L., Rodríguez-Menés, J. (2015). The positional value of education and its effect on general and technical fields of education: educational expansion and occupational returns to education in Spain. European Sociological Review, 32 (2), 216-237.

Perelli-Harris, B., Sigle-Rushton, W., Kreyenfeld, M., Lappegård, T., Keizer, R., \& Berghammer, C. (2010). The educational gradient of childbearing within cohabitation in Europe. Population and Development Review, 36 (4), 775-801.

Raymo, J. M., Iwasawa, M., \& Bumpass, L. (2009). Cohabitation and family formation in Japan. Demography, 46(4), 785-803.

Requena, M. (2005). The secularization of Spanish society: Change in religious practice. South European Society and Politics, 10 (3), 369-390.

Ruggles, S. (2015). Patriarchy, power, and pay: The transformation of American families, 18002015. Demography, 52 (6), 1797-1823.

Seltzer, N. (2019). Beyond the Great Recession: Labor market polarization and ongoing fertility decline in the United States. Demography, 56 (4), 1463-1493. 
Esteve et al. Three Decades Lowest-low Fertility in Spain, 1991-2018

Serrano del Rosar, R., Heredia Cerro, A. (2018). Spanish attitudes towards euthanasia and physician-assisted suicide. Revista Española de Investigaciones Sociológicas, 161, 103-120.

Sobotka, T. (2004). Postponement of childbearing and low fertility in Europe (pp. 298-pp). Amsterdam: Dutch University Press.

Sobotka, T. (2008). Overview chapter 6: The diverse faces of the second demographic transition in Europe. Demographic research, 19, 171-224.

Sobotka, T., \& Beaujouan, É. (2014). Two Is best? The persistence of a two-child family ideal in Europe. Population and Development Review, 40(3), 391-419.

Sobotka, T. (2017). Childlessness in Europe: Reconstructing long-term trends among women born in 1900-1972. In M. Kreyenfeld \& D. Konietzka (Eds.), Childlessness in Europe: Contexts, causes, and consequences. Berlin: Springer, 17-53.

Solsona, M., Simó-Noguera, C. (2007). Evolución histórica del divorcio en España desde la aprobación de la ley de 1981 hasta la reforma de 2004. In A. Cabré \& P Miret (Eds.), La constitución familiar en España. Bilbao: Fundación BBVA, 245-296.

Surkyn, J., \& Lesthaeghe, R. (2004). Value orientations and the second demographic transition (SDT) in Northern, Western and Southern Europe: An update. Demographic research, 3, 4586.

Van de Kaa, D. J. (1987). Europe's second demographic transition. Population bulletin, 42(1), 159.

Vignoli D., Bazzani G., Guetto R., Minello A., Pirani E. (2020) Uncertainty and Narratives of the Future: A Theoretical Framework for Contemporary Fertility. In: Schoen R. (eds) Analyzing 
Esteve et al. Three Decades Lowest-low Fertility in Spain, 1991-2018

Contemporary Fertility. The Springer Series on Demographic Methods and Population Analysis, vol 51. Springer, Cham. https://doi.org/10.1007/978-3-030-48519-1_3

Vikat, A., Spéder, Z., Beets, G., Billari, F. C., Bühler, C., Désesquelles, A., ... \& Sola, A. (2007). Generations and Gender Survey (GGS) Towards a better understanding of relationships and processes in the life course. Demographic research, 17, 389-440.

Voicu, M., Voicu, B., Strapcova, K. (2009). Housework and gender inequality in European countries. European Sociological Review, 25(3), 365-377.

Yu, J., \& Xie, Y. (2015). Cohabitation in China: Trends and determinants. Population and Development Review, 41(4), 607-628. 
Figure 1. Proportion of mothers and fathers and cumulative fertility by age of the cohorts of women and men born in Spain between 1965 and 1989.
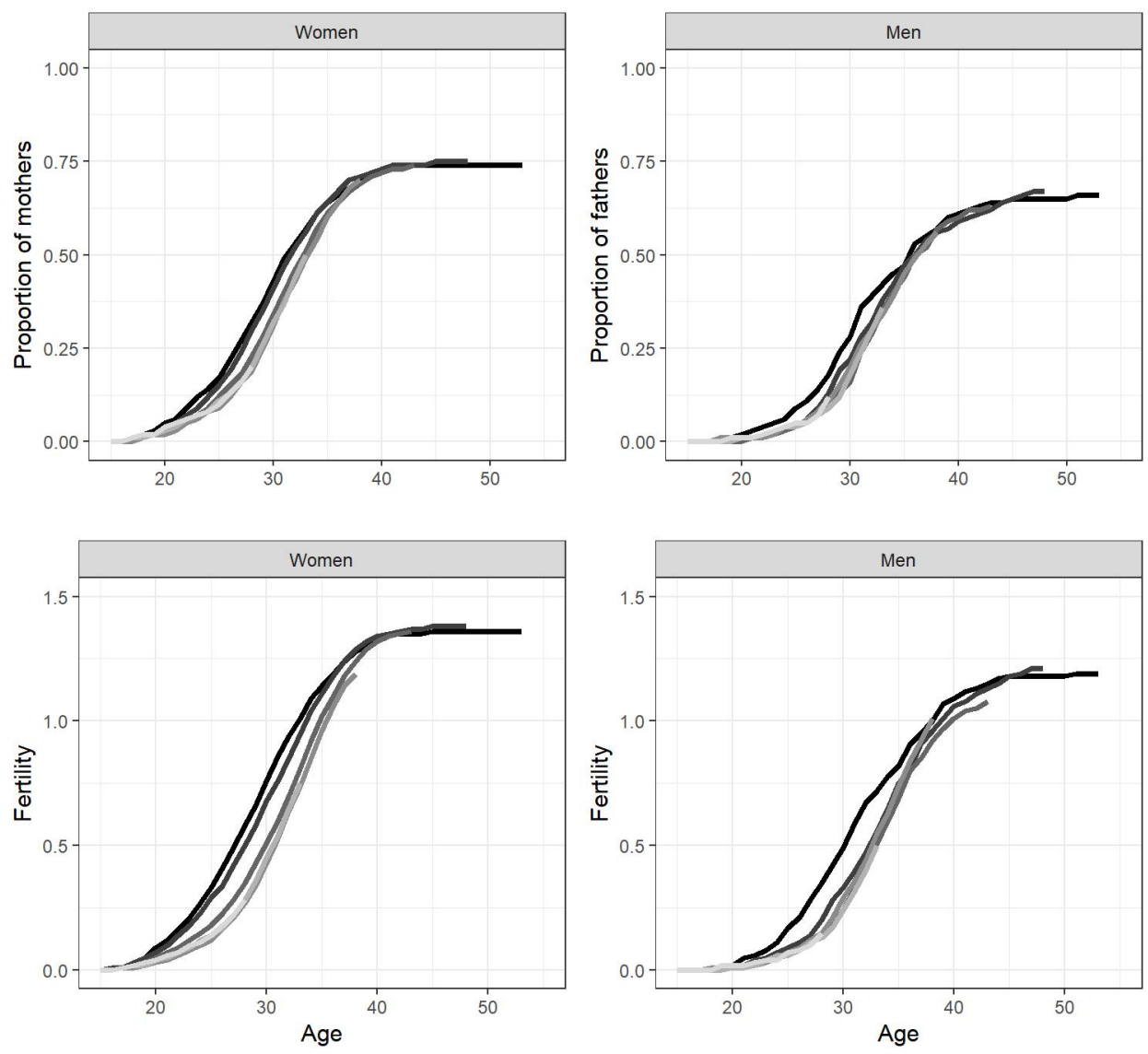

Birth cohort $-1962-1964-1970-1974-1980-1984$

Source: 2018 Fertility Survey, National Institute of Statistics. 
Figure 2. Cumulative proportion of mothers and fathers by age and educational level of the cohorts of women and men born in Spain between 1965 and 1989.

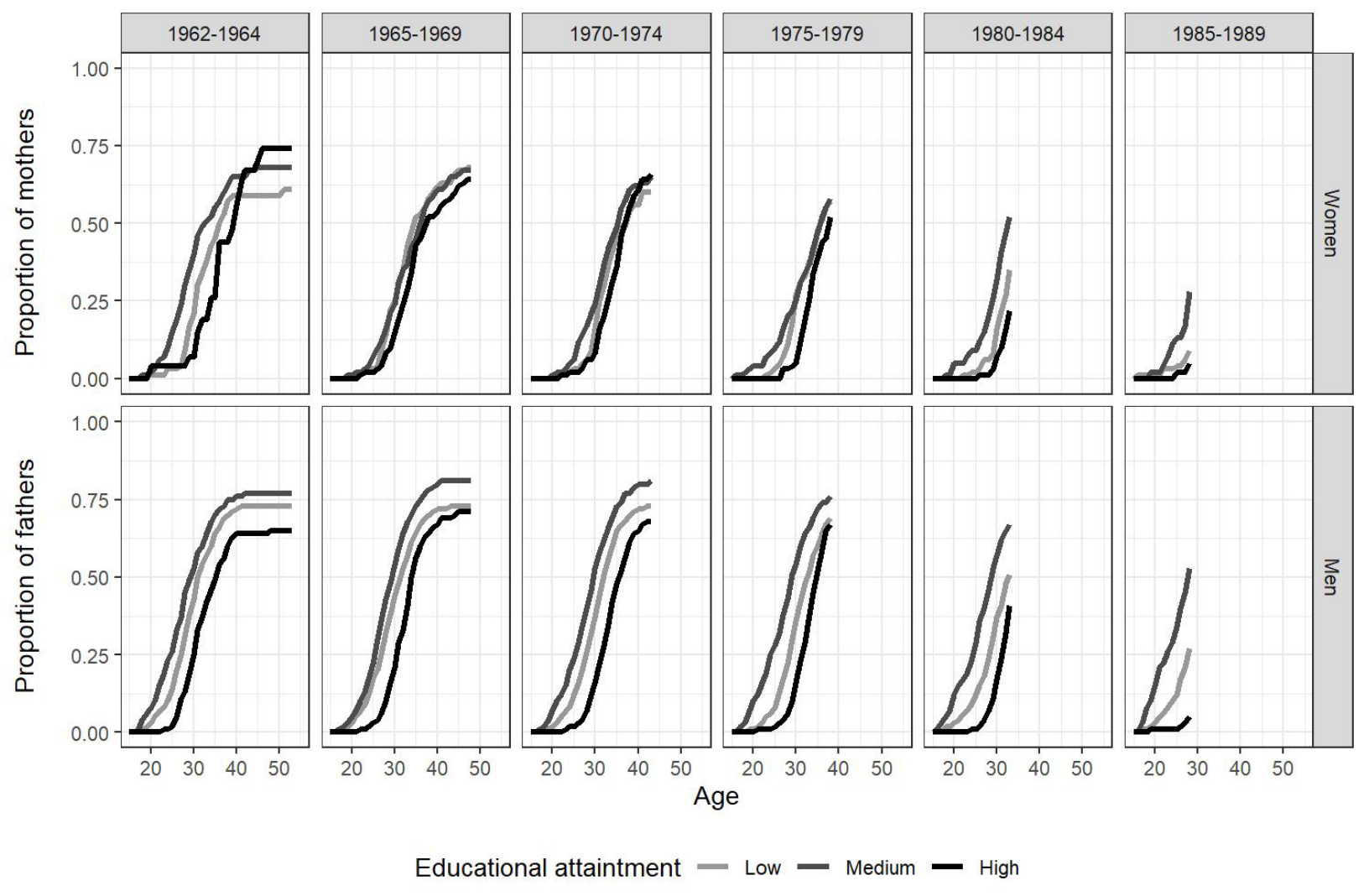

Source: 2018 Fertility Survey, National Institute of Statistics. 
Figure 3. Intention to have children in the next three years by sex, age and parity $(\mathrm{P} 1, \mathrm{P} 2, \mathrm{P} 3)$ at the time of the survey, 2018, of women born in Spain

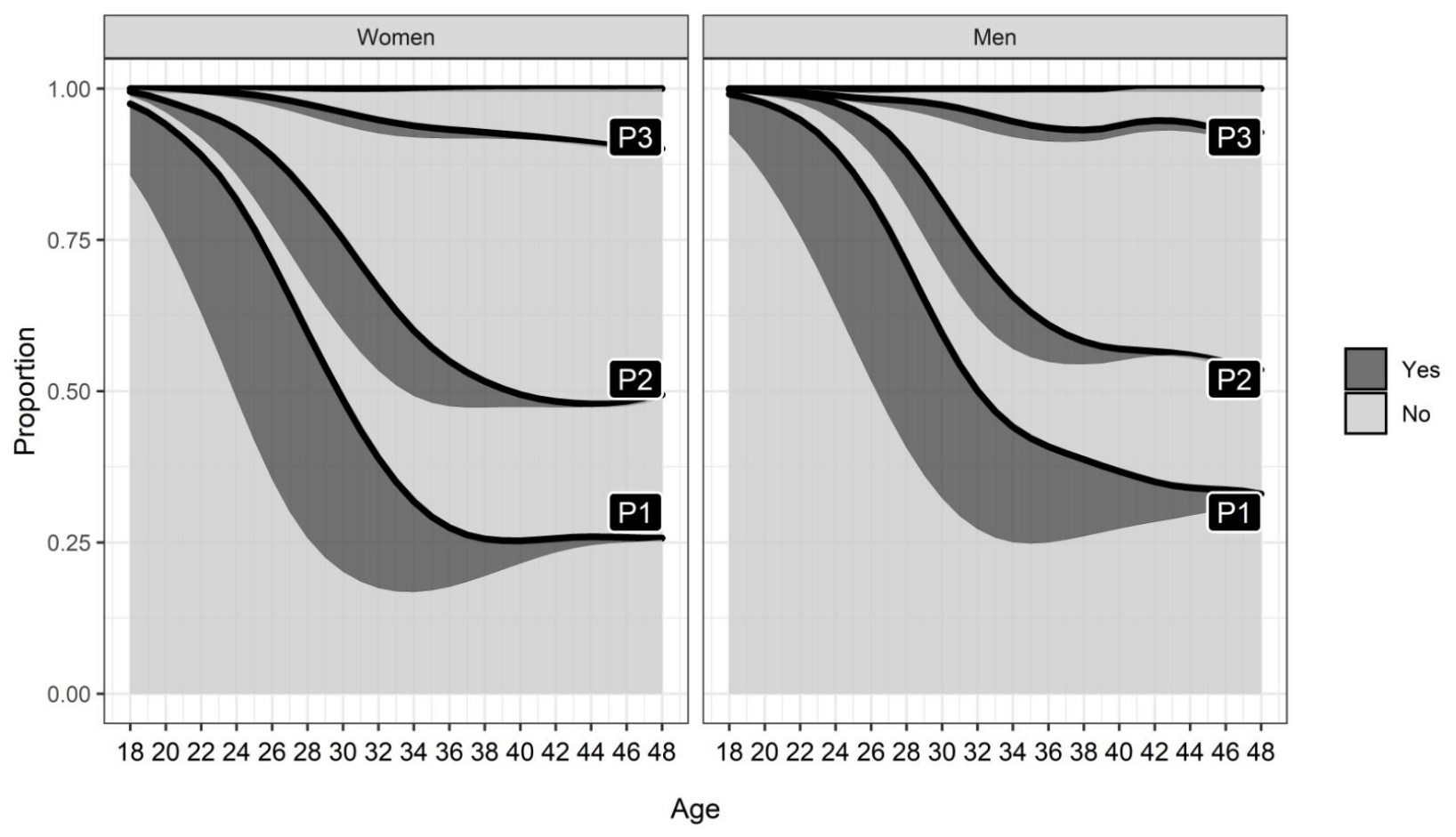

Source: Fertility Survey, National Institute of Statistics 2018. 
Figure 4. Reasons for not having desired number of children by sex, age and parity (P1, P2, P3) at the time of the survey

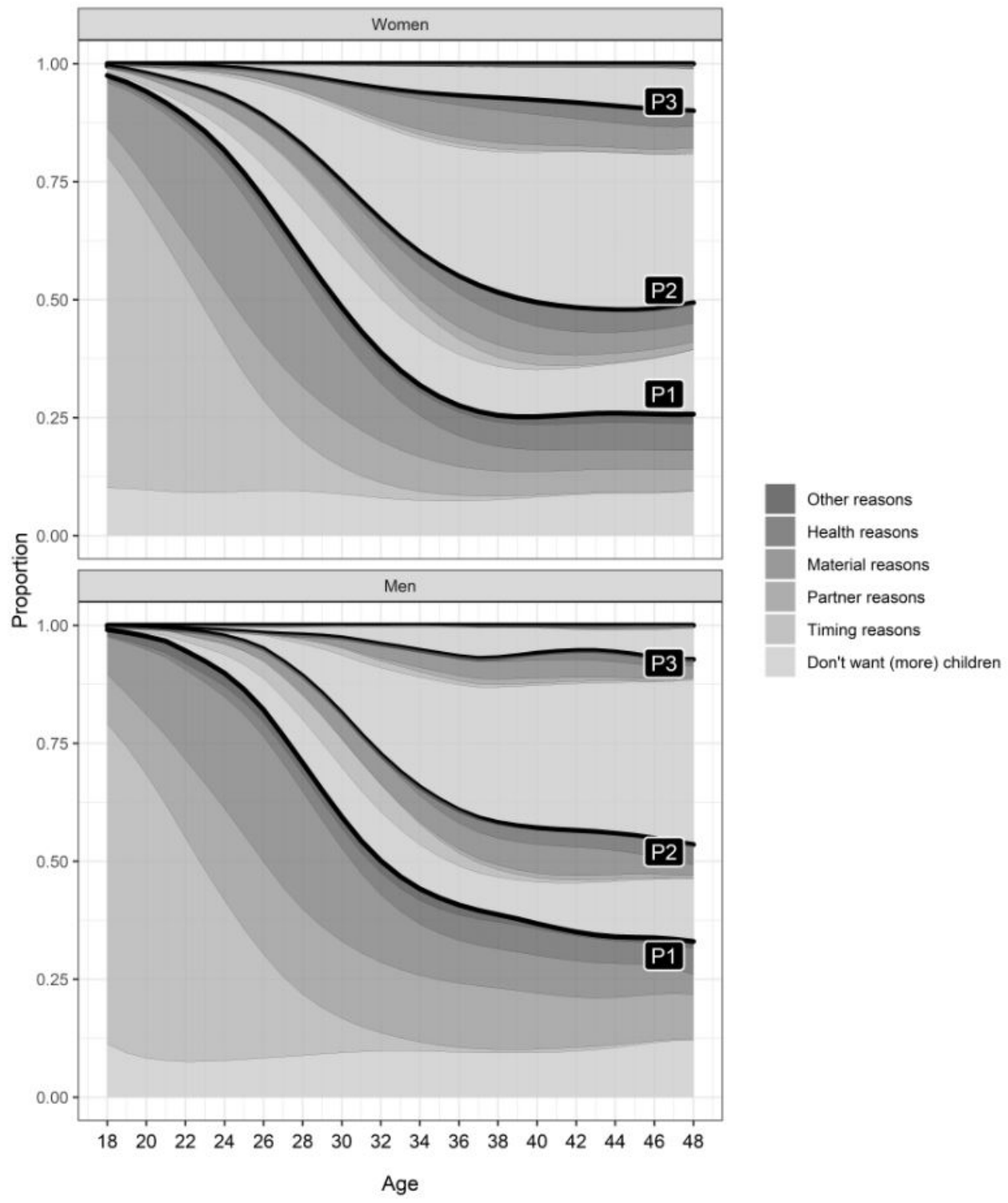

Source: 2018 Fertility Survey, National Institute of Statistics. Only men and women born in Spain 
Esteve et al. Three Decades Lowest-low Fertility in Spain, 1991-2018

Table 1. Unrealized fertility according to the main reported reason by sex, parity and education

\begin{tabular}{|c|c|c|c|c|c|c|c|c|c|c|}
\hline & \multicolumn{5}{|c|}{ Women } & \multicolumn{5}{|c|}{ Men } \\
\hline & \multirow{2}{*}{$\begin{array}{c}\text { Observed } \\
\text { Fertility }\end{array}$} & \multicolumn{4}{|c|}{ unrealized fertility due to..... reasons } & \multirow{2}{*}{$\begin{array}{c}\text { Observed } \\
\text { Fertility }\end{array}$} & \multicolumn{4}{|c|}{ unrealized fertility due to..... reasons } \\
\hline & & Partner & Material & Health & All & & Partner & Material & Health & All \\
\hline \multicolumn{11}{|l|}{ All } \\
\hline Parity 0 & 0,76 & 0,04 & 0,03 & 0,06 & 0,13 & 0,68 & 0,10 & 0,05 & 0,05 & 0,21 \\
\hline Parity 1 & 0,53 & 0,08 & 0,13 & 0,05 & 0,25 & 0,47 & 0,14 & 0,14 & 0,05 & 0,32 \\
\hline Parity $2+$ & 0,09 & 0,06 & 0,13 & 0,02 & 0,22 & 0,07 & 0,17 & 0,23 & 0,02 & 0,43 \\
\hline Total & 1,39 & 0,19 & 0,29 & 0,12 & 0,60 & 1,21 & 0,41 & 0,42 & 0,12 & 0,96 \\
\hline \multicolumn{11}{|c|}{ Education Low } \\
\hline Parity 0 & 0,80 & 0,03 & 0,03 & 0,06 & 0,12 & 0,67 & 0,10 & 0,05 & 0,06 & 0,21 \\
\hline Parity 1 & 0,55 & 0,08 & 0,09 & 0,04 & 0,21 & 0,44 & 0,18 & 0,12 & 0,05 & 0,34 \\
\hline Parity $2+$ & 0,10 & 0,07 & 0,08 & 0,02 & 0,17 & 0,08 & 0,20 & 0,17 & 0,04 & 0,40 \\
\hline Total & 1,45 & 0,18 & 0,19 & 0,12 & 0,50 & 1,19 & 0,47 & 0,34 & 0,15 & 0,94 \\
\hline \multicolumn{11}{|c|}{ Education Medium } \\
\hline Parity 0 & 0,74 & 0,05 & 0,04 & 0,06 & 0,14 & 0,66 & 0,11 & 0,07 & 0,04 & 0,22 \\
\hline Parity 1 & 0,49 & 0,08 & 0,14 & 0,04 & 0,26 & 0,45 & 0,13 & 0,14 & 0,04 & 0,31 \\
\hline Parity 2+ & 0,06 & 0,06 & 0,15 & 0,01 & 0,24 & 0,07 & 0,08 & 0,15 & 0,02 & 0,25 \\
\hline Total & 1,29 & 0,19 & 0,33 & 0,11 & 0,63 & 1,17 & 0,32 & 0,36 & 0,10 & 0,78 \\
\hline \multicolumn{11}{|c|}{ Education High } \\
\hline Parity 0 & 0,72 & 0,06 & 0,04 & 0,05 & 0,15 & 0,68 & 0,10 & 0,06 & 0,04 & 0,20 \\
\hline Parity 1 & 0,52 & 0,10 & 0,15 & 0,05 & 0,29 & 0,54 & 0,12 & 0,13 & 0,06 & 0,30 \\
\hline Parity $2+$ & 0,10 & 0,07 & 0,16 & 0,02 & 0,26 & 0,06 & 0,14 & 0,28 & 0,02 & 0,43 \\
\hline Total & 1,34 & 0,23 & 0,35 & 0,13 & 0,70 & 1,28 & 0,35 & 0,47 & 0,12 & 0,93 \\
\hline
\end{tabular}

Source: Fertility Survey, National Institute of Statistics 2018. 
Figure 5. Probability of having a first child in the next three years according to the couple and employment status at each age of women and men born in Spain between 1965 and 1989
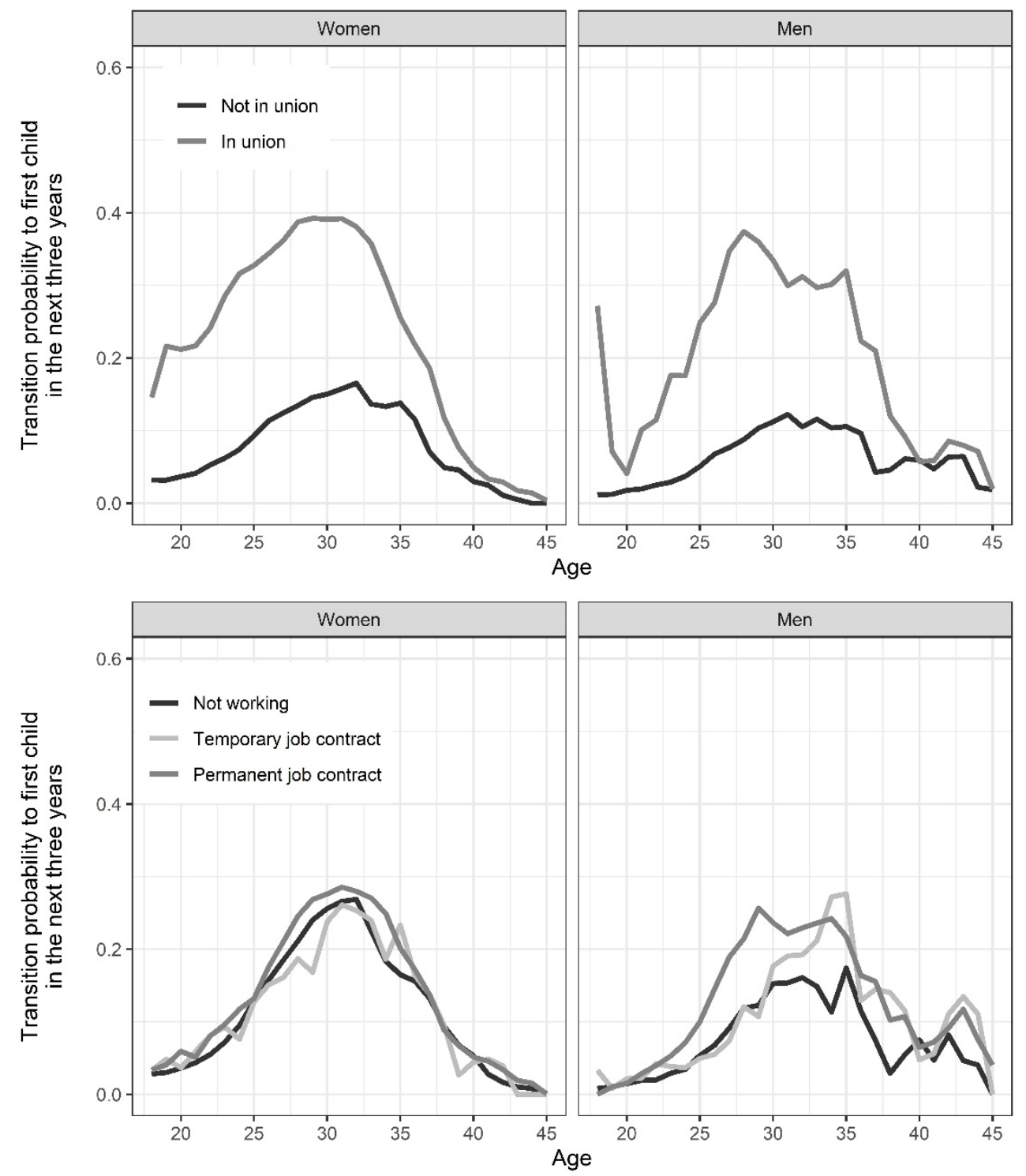

Source: Fertility Survey, National Institute of Statistics 2018. Note: The number of cases among men is much lower than among women, and when dividing the sample by birth cohort the number of cases is further reduced. It is the structure of the data that explains the change in the probability between ages 18 and 20 for male cohabiters. 


\section{Appendix 1. Ranking of reasons for not achieving the desired number of children to date}

Grouping of reasons why women indicated not (yet) having the desired children and of each reason according to parity $(0,1,2,3$; in percentages $)$ - Generations of women born in Spain between 1965 and 1989

\begin{tabular}{|lcccc|}
\hline & \multicolumn{4}{c|}{ Parity } \\
\cline { 2 - 5 } Responses & 0 & 1 & 2 & $3+$ \\
I do not want (more) children & & & & \\
$\quad$ Pregnancies, childbirth and childcare are difficult for women & 0.2 & 1.04 & 1.00 & 1.56 \\
$\quad$ I do not want to be a mother & 5.54 & & & \\
$\quad$ It means losing my freedom and not having time to do other & 0.7 & 0.42 & 0.42 & 0.35 \\
$\quad$ activities & & & & \\
Ideational reasons/ timing & & & & \\
$\quad$ I am too young to have children & 71.49 & & & \\
$\quad$ I am still planning to have more chilren & & 20.48 & 4.8 & 3.01 \\
$\quad$ I want to continue studying & 2.86 & 0.08 & 0.1 & 0.09 \\
Partner reasons & & & & \\
$\quad$ My partner has not wanted to have children/ does not want to yet & 0.34 & 3.25 & 6.2 & 7.22 \\
$\quad$ I do not have a partner or I do not have a suitable partner & 5.85 & 8.93 & 4.00 & 1.67 \\
$\quad$ My partner already has children & & 0.42 & 0.2 & 0.52 \\
Material reasons & & & & \\
$\quad$ Lack or shortage of nursery schools & 0.01 & 0.15 & 0.1 & 0.09 \\
$\quad$ Housing circumstances / Poor housing conditions & 0.05 & 0.75 & 0.9 & 0.56 \\
$\quad$ Work-family conflicts & 1.16 & 18.06 & 24.04 & 25.6 \\
$\quad$ Having children would clash with my career aspirations & 0.82 & 1.04 & 1.15 & 1.04 \\
$\quad$ There is too much work at home & 0.09 & 0.3 & 0.8 & 0.87 \\
$\quad$ Insufficient financial resources & 3.26 & 12.6 & 22.41 & 20.85 \\
$\quad$ Due to my job situation (ot that of my partner) & 2.19 & 3.94 & 3.91 & 3.04 \\
Health reasons & & & & \\
$\quad$ I am too old to have (more) children & 0.62 & 6.51 & 8.54 & 8.25 \\
$\quad$ I could not get pregnant/Unsuccessful pregnancies & 2.29 & 11.97 & 6.61 & 5.65 \\
$\quad$ Health problems & 0.86 & 7.00 & 7.73 & 6.12 \\
$\quad$ Obstacles adopting one/another child & & 0.68 & 0.42 & 0.35 \\
Other reasons & & & & \\
$\quad$ I do not like the current society for a child & 0.54 & & & \\
$\quad$ Concerns/problems in raising children & 0.61 & 0.96 & 1.86 & 1.65 \\
$\quad$ Fear that the child will be born with health issues & 0.25 & 1.18 & 1.2 & 1.21 \\
$\quad$ Other reasons* & 0.27 & 0.24 & 3.61 & 10.3 \\
Total & $100 \%$ & $100 \%$ & $100 \%$ & $100 \%$ \\
\hline
\end{tabular}

Note: for women from parity 1 onwards, includes those who have had more children than desired (e.g., multiple births), although they were later excluded from the analysis.

Source: Fertility Survey 2018, National Institute of Statistics. 


\section{Appendix 2 Method of calculating unrealized fecundity: Obstacle-deleted TFR approach}

The method of calculating unrealized fertility breaks down the difference between observed fertility and desired fertility according to the main factor or reason that has prevented achieving the desired number of children to date. The version presented here is designed for cross-sectional data. We have made three assumptions:

Assumption (1). We treat the data as a "synthetic" cohort, where the numbers at a given age are taken from the situation of persons with that age at the time of interview.

Assumption (2). Each obstacle is independent. In other words, we assume that obstacles related to, for instance, material reasons, are not related to the presence or absence of other types of obstacles. Assumption (3). We simulate a spill-over effect where "resolving" obstacles at a given parity also affect fertility at higher parities.

Based on Assumption (1), the actual TFR is estimated based on the completed fertility observed for persons with the highest age considered here. For example, there are 76 per cent females who have given the first birth at age 48. Then the TFR of the first birth is 0.76 .

Note that this approach is designed for dealing with cross-sectional data. More detailed information about birth history from retrospective questions or from longitudinal data could relax these three assumptions.

In the following parts, we introduce the steps of calculating cause-deleted TFR.

Step 1. Removing obstacle

The proportion of women who have given birth at a given age is calculated as,

$P(x, i)=1-\sum_{h=1}^{i} \sum_{j=1}^{n} O_{j}(x, h)$,

where $x, i$ and $j$ represent age, parity and obstacle, respectively. $n$ is the maximum number of the obstacle. Note that $h$ also indicates parity and $\{h \in \mathbb{Z}: 1 \leq h \leq i\} . O_{j}(x, h)$ is the proportion of females who do not want to give the $h$ th birth due to the obstacle $j$.

Following Assumption (2), if we remove a certain obstacle, the hypothetical proportion of females who have given birth after removing obstacle $j$ is defined as, 
$P_{j}^{*}(x, i)=P(x, i)+O_{j}(x, i)=1-\left[\sum_{h=1}^{i} \sum_{j=1}^{n} O_{j}(x, h)-O_{j}(x, i)\right]$.

Based on Eq. (1), the hypothetical total fertility rate of removing obstacle $j, T F R_{j}{ }^{*}$, can be estimated as,

$\operatorname{TFR}_{j}^{*}(i)=P_{j}^{*}(X, i)$,

where $X$ is the maximum age.

Step 2. Quantifying spill-over effect

Following Assumptions (2) \& (3), removing a certain obstacle at a given parity, will not impact the distribution of other obstacles at the same parity, but does impact the number of births at higher parities. To estimate the spill-over effect, we simulate a completely new hypothetical TFR for higher parities for all individuals of the synthetic cohort. To be more specific, we distribute the proportion females who would give the $(i+1)$ th birth due to removing obstacle $j$, based on the transition ratio from the $i$ th birth to the $(i+1)$ th birth.

The proportion of females who would give the $(i+1)$ th birth is calculated as.

$$
\begin{array}{ll}
\pi_{j}(x, i)=P_{j}{ }^{*}(x, i)-P_{j}{ }^{*}(x-1, i), & x>\text { intial age } \\
\pi_{j}(x, i)=P_{j}{ }^{*}(x, i), & x=\text { intial age }
\end{array}
$$

The transition ratio at age $x$ is defined as,

$$
\begin{array}{ll}
{ }_{i+1} T_{i}(x)=\frac{P(x, i+1)-P(x-1, i+1)}{P(x-1, i)-P(x-1, i+1)}, & x>\text { intial age } \\
{ }_{i+1} T R_{i}(x)=0, & x=\text { intial age }
\end{array}
$$

Note that when transition ratio is negative or over 1 , we force these ratios to 0 or 1 correspondingly. These implausible ratios can arise due to the cross-sectional nature of the data.

The hypothetical TFR of the $(i+1)$ th birth is defined as,

$\operatorname{TFR}_{j}^{*}(i+1)=\sum_{x=a}^{X} f^{*}(x, i+1)$ 
where $f^{*}(x, i+1)$ is the hypothetical age-specific fertility rate of the $(i+1)$ th birth at age $x$, which is calculated as,

$f^{*}(x, i+1)=\sum_{\theta=1}^{X-x} I(x+\theta, i+1), \quad x \neq X-1$

where $I(x, i+1)$ is the contribution to the hypothetical age-specific fertility rate of the $(i+1)$ th birth at age $x .(X-x)$ is the range between maximum age and the targeted age, $x$.

$$
\begin{array}{ll}
I(x+\theta, i+1)=\left[\pi_{j}(x, i)-\sum_{m=1}^{\theta-1} I(x+m, i+1)\right]_{i+1} T R_{i}(x+\theta), & \theta \neq 1 \\
I(x+1, i+1)=\pi_{j}(x, i)_{i+1} T_{i}(x+1) . & \theta=1
\end{array}
$$

where $a$ is the initial age. $m$ and $\theta$ is the increment of age.

To deal with the open the age-group (or, when $x=X-1$ ),

$f^{*}(X-1, i+1)=I(X, i+1)=\left[\pi_{j}(X-1, i)+\pi_{j}(X, i)\right]_{i+1} T R_{i}(x+1)$.

To calculate the iteration term, $I(x+\theta, i+1)$, in Eq. (6), we suggest that the Equations (5), (6), and (7) should be calculated as an entire process rather than separated formulae. For example, if $a=18, x=18$, and $X=48$, and $i=1$ these equations will reduce to,

$$
\begin{aligned}
& \operatorname{TFR}_{j}^{*}(2)=\sum_{x=18}^{48} f^{*}(x, 2) \\
& f^{*}(18,2)=\sum_{\theta=1}^{30} I(18+\theta, 2), \text { and } \\
& I(18+\theta, 2)=\left[\pi_{j}(18,1)-\sum_{m=1}^{\theta-1} I(18+m, 2)\right]{ }_{2} T R_{1}(18+\theta), \quad \theta \neq 1 \\
& I(19,2)=\pi_{j}(18,1){ }_{2} T R_{1}(19) . \quad \theta=1
\end{aligned}
$$

In our analysis, we target three obstacles, namely partner issues, material obstacles, and health problems. The sum of the three obstacles is the total effect of lifting all obstacles considered. We believe that "too young to have a child/No ready" and "Don't want to have a child" reflect the intention to not have (more) children. 